\title{
Yield of screening and diagnostic colonoscopy for polyp and cancer detection
}

\author{
(D) Nidal íflazoğlu, ${ }^{1}$ (1) Ecem Memişoğlu² \\ 'Department of Surgical Oncology, Malatya Training and Research Hospital, Malatya, Turkey \\ ${ }^{2}$ Department of General Surgery, Malatya Training and Research Hospital, Malatya, Turkey
}

\begin{abstract}
Introduction: Colorectal cancer is the third most common disease affecting the global population, with 1.8 million new cases reported per year and a mortality rate of $8 \%$. Currently, the optimum approach to the diagnosis and follow-up of the disease is colonoscopy. The present study aimed to compare the yield of the colonoscopy procedure among ages, genders, reasons for requesting a colonoscopy, presence/absence of family history and presence/absence of polyp/cancer detection history.
\end{abstract}

Materials and Methods: A retrospective examination was made of patients who were referred to the Endoscopy Unit of the Department of General Surgery of our center and who underwent colonoscopy for diagnostic and screening purposes within a three-year period between June 2016 and May 2019.

Results: Of the 2,075 patients included in the study from within the three-year period, 1,181 (57\%) were male and the median age was $45(18-93)$ years. Colonoscopy was performed for screening purposes on $105(5 \%)$ of the patients, while the remaining 1.970 (95\%) patients underwent colonoscopy due to the presence of various symptoms and complaints (bleeding, constipation, diarrhea, abdominal pain, inflammatory bowel disease, etc.). The total polyp detection rate was $13.8 \%$ (287) and the total adenoma detection rate was $9 \%$ (188). Of the patients who underwent colonoscopy, five $(0.26 \%)$ were identified with interval colorectal cancer when the procedure was repeated for various indications.

Conclusion: Colonoscopic examination is the optimum approach to the detection, follow-up, and treatment of colorectal cancer or its precursors. The adenoma detection rates, polyp detection rates, and the interval cancer rates are the guiding tools that point out the importance and quality of colonoscopy.

Keywords: colonoscopy, polyp, cancer

\section{Introduction}

Colorectal cancer is the third most common disease affecting the global population, with 1.8 million new cases reported per year and a mortality rate of $8 \%$. Currently, the optimum approach to the diagnosis and follow-up of the disease (including adenomatous polyps) is colonoscopy. ${ }^{[-3]}$ The lifetime risk of developing colorectal cancer is around $5 \%$ in many regions of the world, and it is known that the colonoscopic resection of adenomatous polyps, as precursors for cancer, reduces both the incidence and mortality related to cancer. ${ }^{[4]}$ The prevalence of adenomas reaches 30\% at 50 years of age and $50 \%$ at 70 years of age ${ }^{[5]}$ The popularity of colonoscopy is based on the technical and technological advances, patient comfort with conscious sedation and the relative safety of the procedure. ${ }^{[6]}$ Colonoscopy has been compared with several methods, such as CT colonoscopy 
and capsule endoscopy, and tendencies toward such procedures may be expected in time. ${ }^{[7,8]}$ Colonoscopy is often associated with certain complications; however, it remains the most popular procedure for the detection and successful removal of polyps ${ }^{[9]}$ When making a decision to perform a procedure, the expected benefit should obviously outweigh the potential risks. Several guidelines have been published on appropriate indications for colonoscopy and the appropriateness of the procedure, among which the most popular are those of the American Society for Gastrointestinal Endoscopy (ASGE) and the European Panel on the Appropriateness of Gastrointestinal Endoscopy (EPAGE) and their various updated versions. ${ }^{[10,11]}$ Being aware of appropriate indications for colonoscopy is very important for the yield of the procedure, with procedural quality and interval cancer development being other important factors.

The present study aims to compare yield of colonoscopy procedure between ages, genders, reasons for requesting a colonoscopy, presence/absence of family history and presence/absence of polyp/cancer detection history. The yield of colonoscopies determined with polyp detection rate (PDR), adenoma detection rate (ADR) and cancer detection rate (CDR). Also, it aims to determine the interval cancer detection rates to compare with the literature.

\section{Materials and Methods}

A retrospective examination was made of patients who were referred to the Endoscopy Unit of the Department of General Surgery of our center, and who underwent colonoscopy for diagnostic and screening purposes within a three-year period between June 2016 and May 2019. Patient data were accessed through the hospital's automated system, and the patient records in the hospital archive were examined when necessary. Those with missing data were excluded from the study. Our study was carried out carefully and sensitively with full adherence to the principles of the Declaration of Helsinki.

Patient demographic data, indications for colonoscopy, presence in family history, indications for re-colonoscopy, results established on colonoscopy and the pathological examination results of patients who underwent biopsies were examined. The pathological examinations of the polyps were performed in accordance with the World Health Organization (WHO) criteria. ${ }^{[12]}$ The polyps were examined under two main groups, as adenomatous and non-adenomatous, and under associated subgroups. The pathologies established on colonoscopy were defined as being either proximally or distally localized to the center of the transverse colon.

Our endoscopy unit is designed in accordance with international standards. ${ }^{[13]}$ As required by the procedural safety and quality control mechanisms of our center, prior to the procedure, the physician determining the need for colonoscopy and recommending the procedure to the patient explains the process to the patient, including potential complications and the patient preparation procedures, in the outpatient clinic.All of the procedures assessed in the present study were carried out by 19 different physicians specialized in General Surgery who were employed in our unit during the study period, and all were experienced in endoscopic procedure.Almost all of the patients were examined under sedation. The patients initiated a pulpless, grainless and liquid diet for two days prior to the colonoscopy. One day before the colonoscopy, the patients were given two doses of $90 \mathrm{ml}$ sodium phosphate as a laxative, and enema was administered twice.

\section{Statistical Analyses}

Categorical variables, expressed as numbers and percentages, were analyzed using $\chi^{2}$ or Fisher's exact test, where appropriate. Continuous variables were expressed as median, or as mean and standard deviation, and $95 \%$ CI as appropriate, and the Student's t-test was used for the comparisons of means. All analyses were performed using the SPSS version 21.0 (SPSS INC, Chicago, IL, United States) software package. A two-tailed $\mathrm{p}<0.05$ was considered statistically significant.

\section{Results}

Of the 2.075 patients included in the study from within the three-year period, 1.181 (57\%) were male, the median age was 45 (18-93) years, and 12 patients with missing data were excluded from the study. Colonoscopy was performed for screening purposes on 105 (5\%) of the patients, while the remaining 1.970 (95\%) patients underwent colonoscopy due to the presence of various symptoms and complaints (bleeding, constipation, diarrhea, abdominal pain, inflammatory bowel disease, etc.). There were $1.249(60.1 \%)$ patients over the age of 50 years, and among these, 154 (7.4\%) had a re-colonoscopy within this period for various reasons (insufficient inspection, cancer, polyp detection, suboptimal inspection, etc.). Of the patients undergoing re-colonoscopy within this period, seven $(4.5 \%)$ and $64(41.8 \%)$ were detected to have cancer and polyps, respectively. The total polyp detection rate was $13.8 \%$ (287) and the total adenoma detection rate was $9 \%$ (188). Of the patients who underwent colonoscopy, five $(0.26 \%)$ were identified with interval colorectal cancer when the procedure was repeated for various indications within the three-year period. The colonoscopy yield was $17.9 \%$ in terms of polyp and cancer detection, and $41.9 \%$ in terms of overall pathologies (Table 1). 
Table 1. Patients features and colonoscopy findings

Variable

All $(n=2075)$

n $\%$

Sex

Male

1181

57

Female

894

43

Age

Median (min-max)

54

$16-93$

Age groups

$\leq 50 \mathrm{yr}$

826

39.9

$>50 \mathrm{yr}$

1249

60.1

Family history

Yes

327

15.8

No

1748

84.2

Indication

Screening

105

Gastrointestinal bleedinga

713

5

Anemia

49

34.3

Constipation

672

2.3

Diarrhea

20

Abdominal pain

344

32.3

Inflammatory bowel disease

69

1

16.5

Others

103

287

3.3

Total Polip Detection

Neoplastic polyps

188

13.8

Non-neoplastic polyps

98

9.1

86

Cancer

153

4.7

4.1

Re-colonoscopy

Polyp detection (yes) Cancer detection (yes)

7.37

After Cancer Surgery

After Polyp Detection

24

25

After Suboptimal Intervention

Other

Total

11

4

64

3

2

1

1

7

No Detection

Total

Polyp Detection Rate (PDR) (\%)

Total

13.8

$>50$ year

17.1

Adenoma Detection Rate (ADR) (\%)

Total

$>50$ year

9

11.2

Interval cancer detection

\begin{tabular}{cc}
$\mathbf{n}$ & $\%$ \\
\hline 5 & 0.26
\end{tabular}

(26 months median follow up)

Total Yield of Interventions

for polyp \& cancer

for overall

41.9

a.including fecal occult blood test positivity. 
Colonoscopic inspections detected adenomatous polyps in 188 patients, and these colonoscopies identified 65.5\% and $9 \%$ of the total patients with polyps detected and all patients undergoing colonoscopy, respectively. Adenomatous polyps were morphologically distributed into 136 (72.3\%) tubular, 33 (17.5\%) tubulovillous, 11 (5.8\%) villous and eight (4.2\%) serrated types. Of the adenomatous polyps, $22.3 \%$ (42) were in patients under 50 years of age, $67.5 \%$ (127) were in male patients and $81.9 \%$ (152) were in distal colonic segments (Table 2).

Of those detected with cancer, $17.4 \%$ (15) were under the age of 50 years. The total cancer detection rate from the colonoscopic procedures was $4.1 \%$ (86). Among the patients detected with cancer, $72 \%$ (62) were male, and cancer was detected in the distal colonic segment in $91.7 \%$ (78).

When cancer and polyp detection was evaluated based on a grouping of patient complaints, statistical significance was noted in the polyp detection rates of the different complaint groups $(\mathrm{p}=0.02)$. An analysis of this significance revealed polyp detection rates to be statistically significantly higher in patients with abdominal complaints (constipation, diarrhea, abdominal pain, inflammatory bowel disease) than in those undergoing colonoscopies for screening purposes. The polyp detection rates among patients with a history of cancer or polyps were statistically significantly higher than among those undergoing colonoscopies for screening purposes. The polyp detection rates among patients with a history of cancer or polyps were statistically significantly higher than those due to GIS bleeding or anemia (Table 3).

When the indications of colonoscopy were grouped (a. Screening, b. GIS bleeding or Anemia, c. Constipation or Diarrhea or Abdominal pain or IBS, d. history of cancer or polyps), no difference was established in the rate of cancer detection between the groups $(\mathrm{p}=0.116)$. An analysis of groups based on age revealed polyp or cancer detection rates statistically significantly higher in those over the age of 50 years $(\mathrm{p}<0.001, \mathrm{p}=0.002$, respectively). The analysis of groups based on gender revealed statistically significantly higher polyp or cancer detection rates in men $(\mathrm{p}<0.001, \mathrm{p}=0.008$, respectively) (Table 3$)$.

\section{Discussion}

The risk of colorectal cancer development shows a clear increase in those over 50 years of age, with those under the age of 50 years accounting for only $10 \%$ of all cases. ${ }^{[14]}$ The

Table 2. Distribution of the histologic types of polyps and cancer by grade of dysplasia, age, gender and location

\begin{tabular}{|c|c|c|c|c|c|c|c|c|c|}
\hline \multirow[t]{2}{*}{ Histologic type of polyps } & \multicolumn{2}{|c|}{$\begin{array}{l}\text { Grade of } \\
\text { dysplasia }\end{array}$} & \multicolumn{2}{|c|}{$\begin{array}{c}\text { Age } \\
\text { groups }\end{array}$} & \multicolumn{2}{|c|}{ Gender } & \multicolumn{2}{|c|}{ Location } & \multirow[t]{2}{*}{ Total } \\
\hline & High & Low & $\begin{array}{c}\leq 50 \mathrm{yr} \\
(\%)\end{array}$ & $\begin{array}{c}>50 \mathrm{yr} \\
(\%)\end{array}$ & $\begin{array}{c}\text { Male } \\
(\%)\end{array}$ & $\begin{array}{c}\text { Female } \\
(\%)\end{array}$ & $\begin{array}{c}\text { Proximal } \\
\text { (\%) }\end{array}$ & $\begin{array}{c}\text { Distal } \\
(\%)\end{array}$ & \\
\hline \multicolumn{10}{|l|}{ Adenomatous polyps } \\
\hline Tubular & 30 & 106 & 31 & 105 & 90 & 46 & 26 & 110 & $136(72.3)$ \\
\hline Tubulo-villous & 11 & 22 & 8 & 25 & 25 & 8 & 7 & 26 & $33(17.5)$ \\
\hline Villous & 7 & 4 & 3 & 8 & 6 & 5 & 2 & 9 & $11(5.8)$ \\
\hline Serrated & 3 & 5 & 0 & 8 & 6 & 2 & 1 & 7 & $8(4.2)$ \\
\hline $\begin{array}{l}\text { Total Adenomatous } \\
\text { polyps }(\% 65.5)\end{array}$ & $\begin{array}{c}51 \\
(27.1)\end{array}$ & $\begin{array}{c}137 \\
(72.8)\end{array}$ & $\begin{array}{c}42 \\
(22.3)\end{array}$ & $\begin{array}{c}146 \\
(77.7)\end{array}$ & $\begin{array}{c}127 \\
(67.5)\end{array}$ & $\begin{array}{c}61 \\
(32.5)\end{array}$ & $\begin{array}{c}36 \\
(19.1)\end{array}$ & $\begin{array}{c}152 \\
(81.9)\end{array}$ & $188(100)$ \\
\hline Hyperplastic polyps & & & 12 & 51 & 35 & 28 & 10 & 53 & $63(63.6)$ \\
\hline Inflammatory polyps & & & 10 & 25 & 23 & 12 & 4 & 31 & $35(35.3)$ \\
\hline Juvenil polips & & & 1 & 0 & 0 & 1 & 0 & 1 & $\begin{array}{c}1(1) \\
99(100)\end{array}$ \\
\hline Total Polyp Detection & & & $\begin{array}{c}64 \\
(22.3)\end{array}$ & $\begin{array}{c}222 \\
(77.7)\end{array}$ & $\begin{array}{c}185 \\
(64.5)\end{array}$ & $\begin{array}{c}102 \\
(35.5)\end{array}$ & $\begin{array}{c}50 \\
(17.4)\end{array}$ & $\begin{array}{c}237 \\
(82.6)\end{array}$ & $\begin{array}{c}287 \\
(100)\end{array}$ \\
\hline Cancer & & & $\begin{array}{c}15 \\
(17.4)\end{array}$ & $\begin{array}{c}71 \\
(82.6)\end{array}$ & $\begin{array}{c}62 \\
(72)\end{array}$ & $\begin{array}{c}24 \\
(28)\end{array}$ & $\begin{array}{c}8 \\
(9.3)\end{array}$ & $\begin{array}{c}78 \\
(91.7)\end{array}$ & $\begin{array}{c}86 \\
(100)\end{array}$ \\
\hline Total polyps \& cancer & & & 79 & 293 & 247 & 126 & 58 & 315 & $373(100)$ \\
\hline
\end{tabular}


Table 3. Comparison of indications, age groups and gender by detecting polyp and cancer

\begin{tabular}{|c|c|c|c|c|c|c|}
\hline \multirow[t]{2}{*}{ Indications } & \multicolumn{2}{|c|}{ Polip } & \multirow[t]{2}{*}{$\mathbf{p}^{y}$} & \multicolumn{2}{|c|}{ Cancer } & \multirow[t]{2}{*}{$\mathbf{p}$} \\
\hline & $\begin{array}{l}\text { Yes, } n(\%) \\
(n=261)\end{array}$ & $\begin{array}{l}\text { No, } n(\%) \\
(n=1765)\end{array}$ & & $\begin{array}{l}\text { Yes, } n(\%) \\
(n=49)\end{array}$ & $\begin{array}{l}\text { No, } n(\%) \\
(n=2026)\end{array}$ & \\
\hline a.Screening & $7(6.7)$ & 98 (93.3) & \multirow[t]{4}{*}{0.02} & 0 & $105(100)$ & \multirow[t]{4}{*}{0.161} \\
\hline b.Gis bleeding or Anemia & $88(11.2)$ & $699(88.8)$ & & $24(2.9)$ & $787(97.1)$ & \\
\hline $\begin{array}{l}\text { c. Constipation or Diarrhea } \\
\text { or Abdominal pain or IBD }\end{array}$ & $152(14.1)$ & $928(85.9)$ & & $25(1.2)$ & $1080(98.8)$ & \\
\hline $\begin{array}{l}\text { d. With cancer or polyp history } \\
\text { Age groups (\%) }\end{array}$ & $14(25.9)$ & $40(74.1)$ & & 0 & $54(100)$ & \\
\hline$\leq 50 \mathrm{yr}$ & $208(2.2)$ & 1049 (97.8) & \multirow[t]{2}{*}{$<0.001$} & $41(3.1)$ & $1257(96.9)$ & \multirow[t]{2}{*}{0.002} \\
\hline$>50 \mathrm{yr}$ & $53(6.8)$ & $716(93.2)$ & & $8(1)$ & $769(99)$ & \\
\hline \multicolumn{7}{|l|}{ Gender, n (\%) } \\
\hline Male & $174(15.2)$ & $969(84.8)$ & \multirow[t]{2}{*}{$<0.001$} & $37(3.1)$ & $1143(96.9)$ & \multirow[t]{2}{*}{0.008} \\
\hline Female & $87(9.9)$ & $796(90.1)$ & & $12(1.3)$ & $883(98.7)$ & \\
\hline
\end{tabular}

$\mathrm{x}$ : Excluding cancers; $\mathrm{y}$ : meaningfulness are between a vs c, a vs d, b vs d, c vs d; IBD: inflammatory bowel disease

prevalence of adenoma is $9-16 \%$, advanced adenoma is $3-6 \%$ and cancer is $0-2.6 \%$ among people over the age of 50 years. ${ }^{[15]}$ This explicit difference between age groups is notable also in the present study, in which 50 years of age is identified as an independent risk factor for the detection of both cancer and polyps. Colorectal cancer is approximately $25 \%$ more common in men than in women, ${ }^{[15]}$ and the findings of the present study are in line with literature in this regard.

Levin et al. ${ }^{[16]}$ reported an annual decrease of $25 \%$ in colorectal cancer incidence, $52.4 \%$ in mortality and $10 \%$ in advance stage incidence when diagnosis is made through screening programs. The EPAGE study by Burnand et al. found no link between patient characteristics and the differences in the appropriateness and performance of screening colonoscopies between centers, although the use of screening colonoscopies in the presence of appropriate indication criteria was noted to enhance procedural efficiency. ${ }^{[17]}$

The colon cancer screening program (CCSP) has been applied in our country since September 2014, based on a fecal occult blood test once every two years and a colonoscopy once every 10 years for healthy individuals aged 50-70 years. ${ }^{[18]}$ The screening process is usually led by the Cancer Early Diagnosis, Screening and Training Centers (KETEMs) affiliated with Primary Care Clinics. It can be said that the screening program in our country does not work to an optimum level for various reasons. An awareness study carried out by Pirincci et al. ${ }^{[19]}$ found that $82.4 \%$ of the respondents were unaware of the existence of KETEM. Furthermore, the cultural structure of society determines the interest in the procedure, with Yakut et al. ${ }^{[20]}$ reporting that asymptomatic individuals over the age of 50 years in our country were not sufficiently interested in screening programs. This may be because the public is not sufficiently informed about the need for screening and how to go about it, and so they fail to internalize the matter. According to the EPAGE II study by Arditi et al., ${ }^{[9]}$ the screening/diagnostic colonoscopy ratio among individuals who have had a colonoscopy varies from $1.8 \%$ to $22.6 \%$, while Burnan et al. ${ }^{[17]}$ reported a ratio of $1 / 10$. The ratio in the present study was around $5 \%$, which is consistent with literature. On the other hand, the screening rate in the present study can be considered relatively low when considering the fact that the individuals over the age of 50 years account for approximately $20-23 \%$ of the population of our country. ${ }^{[21]}$

Colorectal cancer occurs more often in the left colon (including the rectum), ${ }^{[22]}$ although a trend has been observed in the right colon in recent years. ${ }^{[23]}$ Consistent with literature, the present study detected $82.6 \%$ of polyps and $91.7 \%$ of cancers in the left colon. Previous studies have reported $5-10 \%$ of those aged $20-79$ years in the United States and $11.7 \%$ of those aged $30-70$ years in the Netherlands have at least one first-degree relative with colorectal 
cancer. ${ }^{[24,25]}$ The present study detected a family history in $15.8 \%$ of those undergoing colonoscopy, which is believed to be in line with the literature, given the relatively more specific group.

According to ASGE, a considerable number of colonoscopies are performed for inappropriate indications. ${ }^{[2]}$ The study by Burnand et al. suggested that patient characteristics failed to explain the differences in appropriateness and the performance of screening colonoscopies between centers, and that the use of screening colonoscopies under appropriate indication criteria enhanced procedural efficiency ${ }^{[18]}$ In meta-analysis conducted by Hassan C et al., ${ }^{[27]}$ it was reported that the most popular guidelines (ASGE and EPAGE) being followed today fail to identify colorectal cancer patients who do not meet the appropriate indication criteria, and voiced concerns over the use of such guidelines in current clinical practice. Colonoscopy for inappropriate indications has been reported to be more cost effective when compared to the cost of a potential case. In contrast, Bohara et al. ${ }^{[28]}$ found appropriate indications for colonoscopy to be associated with high positive findings, suggesting that the use of guidelines prevents unnecessary procedures. In another paper by Hassan $\mathrm{C}$ et al., ${ }^{[29]}$ it was reported that the cancer detection rate with colonoscopy for an inappropriate indication was $1.9 \%$, while the rate of colonoscopy for an inappropriate indication was $14-37 \%$. According to ASGE, the rate of colonoscopy based on inappropriate indications is $22 \%$. ${ }^{[26]}$ We cannot claim that our center follows the guidelines to the letter in terms of indications for colonoscopy, as the approach of the physician and certain patient characteristics may, of course, change the spectrum of indications. We found that colonoscopy performed on approximately $2 \%(n=41)$ of the patients in our study were for indications that may not be in line with the guidelines, and two (approximately $0.2 \%$ ) of these patients were detected to have adenomatous polyps. Although no cancer was detected in these patients who underwent the procedure for indications not identified in the guidelines, adenomatous polyps, as precursors for cancer, were detected. The retrospective study by Tee et al. ${ }^{[30]}$ highlighted the detection of lesions to be low but not zero among patients who underwent colonoscopy five years after a negative colonoscopy. The strict implementation of the guidelines is controversial in this regard. The performance of the procedure for inappropriate indications may also be influenced by the socioeconomic, psychological and biological characteristics of the population, and extensive screening programs may be a solution to this issue.
Diagnostic yield, which is high in colonoscopies performed for indications of iron deficiency anemia and rectal bleeding, is increased in those over the age of 50 years. ${ }^{[3]]}$ Tumor detection rates are lower in patients with abdominal pain than in those with iron deficiency anemia and rectal bleeding. ${ }^{[32-34]}$ In the present study, rectal bleeding and constipation were the leading indications for colonoscopy, with the two indications accounting for the two-thirds of the total. Although not to a statistically significant degree, GIS bleeding and anemia were the most common indications among those identified with cancer.

A history of colorectal cancer or polyp detection on colonoscopy is an important risk factor for colorectal cancer development; while the histological structure, size and number of polyps are risk factors for the development of metachronous cancer. Polyp or cancer detection is more common in follow-up colonoscopies following a diagnosis of colorectal polyps or cancer, and so those diagnosed with polyps or cancer should undergo a follow-up colonoscopy. Those detected with advanced adenomas or serrated adenomas are at the highest risk of cancer development. The risk increases and the recommended follow-up interval changes with polyp type and increasing diameter or cancer stage. ${ }^{[27,35,36]}$ According to the EPAGE II (5) study, the incidence of metachronous cancer and metachronous polyps at follow-up is $1-25 \%$ (mean: 7.6 ) and $6-40 \%$ (mean: 17.2), respectively. According to the US Multi-Society Task Force on Colorectal Cancer study, ${ }^{[36]}$ colorectal cancer is detected in one of every 157 colonoscopies at follow-up after curative surgery for colorectal cancer, and most lesions are detected within the first 36 months. The present study detected metachronous cancer at follow-up in three patients after cancer and in two patients after polyp detection. In the present study, a higher rate of metachronous lesion detection was reported, with $46.3 \%$ (71/153), while the metachronous cancer rate was $4.7 \%$ (3/63), which is consistent with literature. Most other lesions were polyps, which may be attributed to our relatively low number of follow-up colonoscopies, and should also serve as a warning of the danger of missing polyps during colonoscopy procedures.

The rates reported in colonoscopy screening studies vary from $4.9 \%$ to $8.6 \%$ for advanced adenoma detection, and from $14.9 \%$ to $37.5 \%$ for any adenoma or cancer detection. ${ }^{[37]}$ Corley et al. ${ }^{[38]}$ reviewed 314.872 colonoscopy procedures, and found the polyp detection rate (PDR) to vary between $7.5 \%$ and $52 \%$, and the authors further re- 
ported an interval cancer detection of 4.8-9.8 during the follow-up of 10.000 patients per year. The EPAGE study ${ }^{[40]}$ determined a PDR of $12.5 \%$, while the meta-analysis by Hassan et al. ${ }^{[29]}$ found the cancer detection rate and adenomatous polyp detection rates to be $4.4 \%$ and $14.7 \%$, respectively. Rulyak et al. identified an interval cancer rate of $2.8 \%$ among patients detected with colorectal cancer. ${ }^{[39]}$ The interval cancer rate $(<1 \%)$ established in the present study was quite low when compared to literature.

Tubular adenomas have a rate of $80 \%$ among all polyp types, while the rate of tubular adenomas was $72.3 \%$ in the present study, which is similar to literature. ${ }^{[40,41]} \mathrm{An}$ adenoma is considered advanced when greater than $1 \mathrm{~cm}$, or when exhibiting a villous structure or high-grade dysplasia. Low- or high-grade dysplasia can be noted in all adenomas, and is the middle stage in the development of a polyp into cancer. ${ }^{[40-42]}$ Adenomas account for two-thirds of all polyps, ${ }^{[43]}$ and so the rate (65.5\%) established in the present study can be considered consistent with literature.

It is reported that the desired cecal intubation rate is $\geq 95 \%$ and the acceptable rate is $\geq 90 \%$ in patients scheduled for total colonoscopy. ${ }^{[44,45]}$ Adenomatous polyp detection rate, cecal intubation rate and colonic inspection times are among the quality metrics. According to the US Multi-Society Task Force, a high-quality colonoscopy should involve a cecal intubation rate of $\geq 95 \%$, minimum fecal debris and a retrograde colonic inspection of the cecum lasting 6-10 minutes. ${ }^{[36]}$ Faminski et al. ${ }^{[46]}$ identified a significantly higher likelihood of development of interval cancer when the polyp detection rate was $20 \%$ and below, and suggested a polyp detection rate of $\geq 20 \%$ to be a quality indicator for endoscopy. The ADR and Cancer Detection Rate (CDR) found in the present study are close to the values reported in literature, while the estimated interval cancer rates are similar to the literature.

The Poland study reports an ADR of $\leq 20 \%$ to be associated with a 10 times or more interval cancer detection. ${ }^{[48]}$ In Corley et al.'s ${ }^{[38]}$ comparison of $33.5 \%$ and $19 \%$ ADRs, it was found to be an independent risk factor for interval cancer, and an increase of $1 \%$ in ADR in particular was noted to result in a decrease of $3 \%$ in interval cancer. Tjaden et al. ${ }^{[47]}$ considered the criterion for a high-quality colonoscopy to be $25 \%$ ADR. The ADR and PDR identified in the present study are similar to those reported in literature, although our rates can be considered low considering the criteria for high-quality colonoscopy. Unexpectedly, despite the low ADR and PDR values, the interval cancer rate in the present study was considerably lower than that reported in literature. We believe that this may be a result of our decision to apply colonoscopy for a wide range of indications.

Colonoscopic examination is the optimum approach to the detection, follow-up and treatment of colorectal cancer or its precursors. Considering the parameters used to establish the yield and quality of the procedure, the ADRPDR and the interval cancer rates in literature, we believe some behavioral changes may take place around the world. The present study will serve as a guide for prospective studies.

\section{Disclosures}

Ethichs Committee Approval: The study was approved by the Local Ethics Committee. (Malatya Training and Research Hospital, 25.06.2019/8941).

Peer-review: Externally peer-reviewed.

Conflict of Interest: None declared.

Authorship Contributions: Concept -E.M., N.İ.; Design - N.İ; Supervision - E.M., N.İ.; Materials - E.M.; Data collection and/or processing - E.M.; Analysis and/ or interpretation - N.İ., E.M.; Literature search - N.İ.; Writing - N.İ.; Critical review - N.İ., E.M.

\section{References}

1. Inadomi JM, Vijan S, Janz NK, Fagerlin A, Thomas JP, Lin YV, et al. Adherence to colorectal cancer screening: a randomized clinical trial of competing strategies. Arch Intern Med 2012;172:575-82. [CrossRef]

2. Levin B, Lieberman DA, McFarland B, Andrews KS, Brooks D, Bond J, et al. Screening and surveillance for the early detection of colorectal cancer and adenomatous polyps, 2008: a joint guideline from the American Cancer Society, the US Multi-Society Task Force on Colorectal Cancer, and the American College of Radiology. Gastroenterology 2008;134:1570-95.

3. Winawer SJ, Zauber AG, Fletcher RH, Stillman JS, O'Brien MJ, Levin B, et al. Guidelines for colonoscopy surveillance after polypectomy: a consensus update by the US Multi-Society Task Force on Colorectal Cancer and the American Cancer Society. Gastroenterology 2006;130:1872-85. [CrossRef]

4. Schreuders EH, Ruco A, Rabeneck L, Schoen RE, Sung JJ, Young GP, et al. Colorectal cancer screening: a global overview of existing programmes. Gut 2015;64:1637-49. [CrossRef]

5. Arditi C, Gonvers JJ, Burnand B, Minoli G, Oertli D, Lacaine F, et al. Appropriateness of colonoscopy in Europe (EPAGE II). Surveillance after polypectomy and after resection of colorectal cancer. Endoscopy 2009;41:209-17. [CrossRef]

6. Gimeno-García AZ, Quintero E. Colonoscopy appropriate- 
ness: Really needed or a waste of time?. World J Gastrointest Endosc 2015;7:94-101. [CrossRef]

7. May A, Manner H, Schneider M, Ipsen A, Ell C. Prospective multicenter trial of capsule endoscopy in patients with chronic abdominal pain, diarrhea and other signs and symptoms (CEDAPPlus Study). Endoscopy 2007;39:606-12. [CrossRef]

8. Cotton PB, Durkalski VL, Pineau BC, Palesch YY, Mauldin PD, Hoffman B, et al. Computed tomographic colonography (virtual colonoscopy): a multicenter comparison with standard colonoscopy for detection of colorectal neoplasia. JAMA 2004;291:1713-19. [CrossRef]

9. Arditi C, Peytremann-Bridevaux I, Burnand B, Eckardt VF, Bytzer P, Agreus L, et al. Appropriateness of colonoscopy in Europe (EPAGE II). Screening for colorectal cancer. Endoscopy 2009;41:200-8. [CrossRef]

10. Appropriate use of gastrointestinal endoscopy. American Society for Gastrointestinal Endoscopy. Gastrointest Endosc 2000;52:831-7. [CrossRef]

11. Froehlich F, Pache I, Burnand B, Vader JP, Fried M, Beglinger $C$, et al. Performance of panel-based criteria to evaluate the appropriateness of colonoscopy: a prospective study. Gastrointest Endosc 1998;48:128-36. [CrossRef]

12. Heitman SJ, Ronksley PE, Hilsden RJ, Manns BJ, Rostom A, Hemmelgarn BR. Prevalence of adenomas and colorectal cancer in average risk individuals: a systematic review and metaanalysis. Clin Gastroenterol Hepatol 2009;7:1272-8. [CrossRef]

13. International Health Facility Guidelines. Endoscopy unit. Available at: http://healthfacilityguidelines.com/ViewPDF/ ViewIndexPDF/iHFG_part_b_endoscopy_unit. Accessed Jun 29, 2020.

14. Fleshner $P$, Slater $G$, Aufses $A H$ jr. Age and sex distribution of patients with colorectal cancer. Dis Colon Rectum 1989;32:107-11. [CrossRef]

15. Jemal A, Siegel R, Xu J, Ward E. Cancer statistics, 2010. CA Cancer J Clin 2010;60:277-300. [CrossRef]

16. Levin TR, Corley DA, Jensen CD, Schottinger JE, Quinn VP, Zauber $A G$, et al. Effects of Organized Colorectal Cancer Screening on Cancer Incidence and Mortality in a Large Community-Based Population. Gastroenterology 2018;155:1383-91. [CrossRef]

17. Burnand B, Harris JK, Wietlisbach V, Froehlich F, Vader JP, Gonvers JJ. Use, appropriateness, and diagnostic yield of screening colonoscopy: an international observational study (EPAGE). Gastrointest Endosc 2006;63:1018-26. [CrossRef]

18. T.C. Sağlık Bakanlığı Kanser İstatistikleri. Available at: https://hsgm.saglik.gov.tr/tr/kanser-istatistikleri. Accessed Jun 29, 2020.

19. Pirinççi S, Benli C, Okyay P. Patients admitted to tertiary health care center colorectal cancer screening program awareness study. TAF Preventive Medicine Bulletin 2015;14:209-14.

20. Yakut M, Uysal E, Beşik G, Özkan Y, Kırbaş G, Özden A. How do Turkish people perceive colonoscopy procedure? A Research on the factors effecting adaptation to colonoscopic preliminary diet: A clinical prospective study. Endoskopi Gastrointestinal 2009;17:69-71.

21. TÜIK. Available at: http://www.tuik.gov.tr/HbGetirHTML. do?id=33705. Accessed May 31, 2020.

22. Ahnen DJ, Wade SW, Jones WF, Sifri R, Mendoza Silveiras $\mathrm{J}$, Greenamyer J, et al. The increasing incidence of youngonset colorectal cancer: a call to action. Mayo Clin Proc 2014;89:216-24. [CrossRef]

23. Troisi RJ, Freedman AN, Devesa SS. Incidence of colorectal carcinoma in the U.S.: an update of trends by gender, race, age, subsite, and stage, 1975-1994. Cancer 1999;85:167076. [CrossRef]

24. Lowery JT, Ahnen DJ, Schroy PC 3rd, Hampel H, Baxter N, Boland $\mathrm{CR}$, et al. Understanding the contribution of family history to colorectal cancer risk and its clinical implications: A state-of-the-science review [published correction appears in Cancer. Cancer 2016;122:2633-45. [CrossRef]

25. Wilschut JA, Steyerberg EW, van Leerdam ME, Lansdorp-Vogelaar I, Habbema JD, van Ballegooijen M. How much colonoscopy screening should be recommended to individuals with various degrees of family history of colorectal cancer?. Cancer 2011;117:4166-74. [CrossRef]

26. Balaguer F, Llach J, Castells A, Bordas JM, Ppellise M, Rodriguez-Moranta $F$, et al. The European panel on the appropriateness of gastrointestinal endoscopy guidelines colonoscopy in an open-access endoscopy unit: a prospective study. Aliment Pharmacol Ther 2005;21:609-13. [CrossRef]

27. Hassan C, Di Giulio E, Pickhardt PJ, Zullo A, Laghi A, Kim DH, et al. Cost effectiveness of colonoscopy, based on the appropriateness of an indication. Clin Gastroenterol Hepatol 2008;6:1231-36. [CrossRef]

28. Bohara TP, Laudari U, Thapa A, Rupakheti S, Joshi MR. Appropriateness of Indications of Upper Gastrointestinal Endoscopy and its Association With Positive Finding. JNMA J Nepal Med Assoc 2018;56:504-9. [CrossRef]

29. Hassan C, Di Giulio E, Marmo R, Zullo A, Annibale B. Appropriateness of the indication for colonoscopy: systematic review and meta-analysis. J Gastrointestin Liver Dis 2011;20:279 86.

30. Tee CL, Stephensen B, Sloss A, Grieve DA. Yield of adenomas and colorectal cancers within 5 years of a negative colonoscopy: are the guidelines guiding?. ANZ J Surg 2018;88:E1-E5.

31. Terraz O, Wietlisbach V, Jeannot JG, Burnand B, Froehlich F, Gonvers JJ, et al. The EPAGE internet guideline as a decision support tool for determining the appropriateness of colonoscopy. Digestion 2005;71:72-7. [CrossRef]

32. Kueh SH, Zhou L, Walmsley RS. The diagnostic yield of colonoscopy in patients with isolated abdominal pain. N Z Med J 2013;126:36-44.

33. Bjerrum A, Andersen O, Fischer A, Lindebjerg J, Lynge E. Longterm risk of colorectal cancer after negative colonoscopy in a Danish gFOBT screening cohort. Int J Cancer 2017; 141:50311. [CrossRef]

34. Ford AC, Veldhuyzen van Zanten SJ, Rodgers CC, Talley NJ, Vakil NB, Moayyedi P. Diagnostic utility of alarm features for colorectal cancer: systematic review and meta-analysis. Gut 2008;57:1545-53. [CrossRef]

35. Gupta S, Lieberman D, Anderson JC, Burke CA, Dominitz JA, 
Kaltenbach T, et al. Recommendations for Follow-Up After Colonoscopy and Polypectomy: A Consensus Update by the US Multi-Society Task Force on Colorectal Cancer. Gastrointest Endosc 2020;91:463-85.e5. [CrossRef]

36. Click B, Pinsky PF, Hickey T, Doroudi M, Schoen RE. Association of Colonoscopy Adenoma Findings With Long-term Colorectal Cancer Incidence. JAMA 2018;319:2021-31. [CrossRef]

37. Moss S, Ancelle-Park R, Brenner H; International Agency for Research on Cancer. European guidelines for quality assurance in colorectal cancer screening and diagnosis. First Edition--Evaluation and interpretation of screening outcomes. Endoscopy 2012;44:SE49-SE64. [CrossRef]

38. Corley DA, Jensen CD, Marks AR, Zhao WK, Lee JK, Doubeni $\mathrm{CA}$, et al. Adenoma detection rate and risk of colorectal cancer and death. N Engl J Med 2014;370:1298-306. [CrossRef]

39. Rulyak SJ, Lieberman DA, Wagner EH, Mandelson MT. Outcome of follow-up colon examination among a populationbased cohort of colorectal cancer patients. Clin Gastroenterol Hepatol 2007;5:470-7. [CrossRef]

40. Laiyemo AO, Murphy G, Sansbury LB, Wang Z, Albert PS, Marcus PM, et al. Hyperplastic polyps and the risk of adenoma recurrence in the polyp prevention trial. Clin Gastroenterol Hepatol 2009;7:192-7. [CrossRef]

41. Zbuk KM, Eng C. Hamartomatous polyposis syndromes. Nat
Clin Pract Gastroenterol Hepatol 2007;4:492-502. [CrossRef]

42. The Paris endoscopic classification of superficial neoplastic lesions: esophagus, stomach, and colon: November 30 to December 1, 2002. Gastrointest Endosc 2003;58:S3-S43.

43. Carlsson G, Petrelli NJ, Nava H, Herrera L, Mittelman A. The value of colonoscopic surveillance after curative resection for colorectal cancer or synchronous adenomatous polyps. Arch Surg 1987;122:1261-63. [CrossRef]

44. Loffeld RJ, Liberov B, Dekkers PE. The yearly prevalence of findings in endoscopy of the lower part of the gastrointestinal tract. ISRN Gastroenterol 2012;2012:527634. [CrossRef]

45. von Karsa L, Patnick J, Segnan N. European guidelines for quality assurance in colorectal cancer screening and diagnosis. First Edition-Executive summary. Endoscopy 2012;44:SE1-8. [CrossRef]

46. Kaminski MF, Regula J, Kraszewska E, Polkowski M, Wojciechowska U, Didkowska J, et al. Quality indicators for colonoscopy and the risk of interval cancer. $\mathrm{N}$ Engl $\mathrm{J}$ Med 2010;362:1795-03. [CrossRef]

47. Tjaden JM, Hause JA, Berger D, Duveneck SK, Jakate SM, Orkin BA, et al. Adenoma detection rate metrics in colorectal cancer surveillance colonoscopy. Surg Endosc 2018;32:3108-13. [CrossRef] 